Nloma 2015, 33(1), 43-53

Revista de Psicologia, Ciències de l'Educació i de l'Esport

ISSN: 1138-3194

Copyright $(92015$

www.revistaaloma.net

\title{
Aplicación del subtitulado como herramienta logopédica para trabajar el lenguaje escrito con niños con discapacidad auditiva
}

\author{
Minia Porteiro-Fresco \\ Universitat Ramon Llull
}

Recibido: 26-1-2015

Aceptado: 7-4-2015

Aplicación del subtitulado como herramienta logopédica para trabajar el lenguaje escrito con niños con discapacidad auditiva

Resum. En la actual sociedad de la información en la que vivimos inmersos, el uso de medios audiovisuales con finalidad docente está muy extendido, en este sentido se puede destacar el uso de los subtítulos, que ofrecen un gran potencial didáctico reconocido. Este hecho, sumado a la cada vez mayor necesidad de encontrar recursos que permitan a los logopedas diseñar material adaptable a las exigencias y preferencias de sus pacientes es lo que ha favorecido que se haya planteado extender el uso de esta técnica al ámbito logopédico. El objetivo de este artículo, por lo tanto, es ofrecer una propuesta para trabajar el aprendizaje de la lectura y la escritura con niños con discapacidad auditiva aplicando material audiovisual subtitulado y en un contexto logopédico.

Palabras clave: subtitulado, lectoescritura, logopedia, sordera

Use of subtitling as a tool in speech therapy to work on written language with hearing impaired children

Summary. In the context of the contemporary information society that surrounds us, the use of audio-visual media for teaching purposes is very widespread, with one particularly noteworthy area being the use of subtitles, whose educational potential is recognized. This reality, along with the ever-increasing need to find resources that allow speech therapists to design materials that their patients' demands and preferences, has been the impetus for a consideration of an expanded use of this technique in the sphere of speech therapy. Thus, this article aims to offer a proposal to work with children with hearing impairments to teach them reading and writing through the application of subtitled audio-visual materials in the context of speech therapy.

Keywords: subtitling, reading and writing teaching, speech therapy, hearing impairment

Correspondencia

Minia Porteiro Fresco

Facultat de Psicologia, Ciències de l’Educació i de l'Esport Blanquerna,

Universitat Ramon Llull C/Císter núm. 34, 08022 Barcelona

Email: miniapf@blanquerna.url.edu 


\section{Introducción}

El/la logopeda generalmente se surte de una amplia variedad de herramientas o recursos para desarrollar sus sesiones de intervención de la forma más eficaz y dinámica posible. Sin embargo, cada vez con más frecuencia, debido a la necesidad de buscar materiales que se adapten a pacientes con perfiles muy heterogéneos, el logopeda crea su propio material muchas veces con ayuda de los recursos tecnológicos que tiene a su alcance, en especial, el uso del ordenador. En la actual sociedad de la información en la que vivimos inmersos, el uso de medios audiovisuales con finalidad docente está muy extendido. En este sentido se puede destacar el uso de los subtítulos que ofrecen un gran potencial didáctico reconocido. Este hecho, sumado a la cada vez mayor necesidad de encontrar recursos que permitan a los logopedas diseñar material adaptable a las exigencias y preferencias de sus pacientes es lo que ha favorecido que se haya planteado extender el uso de esta técnica al ámbito logopédico, tal y como se verá a lo largo de este artículo.

El objetivo, por lo tanto, es ofrecer una propuesta para trabajar la lectura y escritura, y por extensión el lenguaje, con niños con discapacidad auditiva utilizando material audiovisual subtitulado en un contexto logopédico.

\section{Material audiovisual subtitulado con finalidad didáctica}

Los medios audiovisuales se han ido convirtiendo, a lo largo de las últimas décadas, en la principal fuente de información de los acontecimientos que suceden en el mundo. Además de jugar un papel informativo, y sin olvidar su gran potencial lúdico, los medios audiovisuales nos proporcionan un input lingüístico variado y cercano al receptor (Naigles \& Mayeux, 2000). Pero, además, desde hace unos años, diferentes autores coinciden en subrayar la importancia del material audiovisual como herramienta extrapolable al ámbito educativo (Podszebka, Colin, Apple \& Windus, 1998; Baltova, 1999; Brett \& Nash, 1999; Bachetti, 2003; Danan, 2004; Linebarger, 2006; Cambra, Silvestre \& Leal, 2010).

En este sentido, Bachetti (2003) destaca la flexibilidad del material audiovisual para poder adaptarlo a los intereses del alumnado. Con un input inteligible y atractivo se consigue aumentar la motivación ante un aprendizaje y se ve reducida considerablemente la ansiedad que el enfrentamiento al nuevo aprendizaje puede conllevar. En el momento en que un material didáctico no capta la atención y el interés de un alumno se activa lo que Krashen (1985) llama filtro afectivo que existe entre nuestros órganos de percepción y nuestro mecanismo de adquisición del lenguaje; filtro que se acciona ante situaciones de ansiedad, autoestima baja y falta de motivación. Si el filtro afectivo está activado, el estudiante sufre un bloqueo ante el input, por ello Krashen (1985) mantiene que es tan impor- tante fomentar un ambiente relajado y que despierte el interés del alumno ante la presencia de un material didáctico. Si los estudiantes están aburridos, nerviosos, frustrados o poco motivados, su actitud será mucho menos receptiva ante la presencia de un nuevo input lingüístico.

El material audiovisual es una fuente rica en input lingüístico y funciona como reclamo para el receptor por su contenido y formato cautivador, además de por su cercanía por el lenguaje empleado. Por esta razón, se convierte en un elemento motivador que puede preparar al receptor ante un nuevo aprendizaje. La ubicuidad y el atractivo del material audiovisual ofrecen una oportunidad única e innegable para enriquecer la vida de los niños a través de programas educativos de calidad (Linebarger, 2006). El material audiovisual puede presentarse por diversos canales y en diferentes formatos, una vez más, Krashen (1985) propone el subtitulado como una técnica adecuada para evitar la activación del filtro afectivo, ya que los subtítulos ofrecen un input inteligible para los estudiantes y, además, resulta relativamente sencillo encontrar material audiovisual que se adapte a sus intereses y preferencias particulares. Con la utilización de subtítulos para el desarrollo de materiales auxiliares, se puede aumentar el interés por el aprendizaje de la lectura en los niños que se enfrentan a la pantalla con habilidades y estilos de aprendizaje muy diferentes (Linebarger, Taylor-Piotrowski \& Vaala, 2007). Así lo entienden algunos autores cuando afirman «los alumnos que utilizan material subtitulado demuestran una mejora en la comprensión lectora, comprensión auditiva, aprendizaje de vocabulario, reconocimiento de palabras, habilidades para descodificar y, en general, motivación por leer» (Parks, 1994: 2).

Una de las propuestas más repetidas para favorecer el aprendizaje y la motivación por la lectura es la de incorporar actividades relacionadas con la lectura en la vida diaria, ya que ayuda a entender la lectura como un objetivo de valor social. Es lo que se entiende por lectura emergente, concepto que sugiere que la exposición a actividades relacionadas con la lectura, dentro de un contexto social, fomenta su aprendizaje (Jelinek, 1999; Stark, 2010). En 1984, Posell ya había hecho referencia a este aspecto al afirmar que la habilidad lectora mejora ampliablemente con la práctica y considera que leer subtítulos es una forma divertida de practicar la lectura.

\subsection{El subtitulado. Tipos de subtítulos}

El objetivo de este artículo no es detenerse a analizar la clasificación de los diferentes tipos de subtítulos ${ }^{1}$ existentes en el mercado, no obstante, resulta necesario aclarar que cuando se habla de la técnica del subtitulado se debe tener muy presente que existen diferencias

\footnotetext{
${ }^{1}$ Para profundizar sobre el tipo de subtítulos se recomienda consultar la taxonomía propuesta por Bartoll, 2012.
} 
importantes entre los tipos de subtítulos y que se pueden clasificar atendiendo a una serie de parámetros textuales, pragmáticos y técnicos (Bartoll, 2012) algunos de los cuales se describen, de manera abreviada, a continuación. Sin embargo, en primer lugar, conviene recordar qué se entiende por subtítulo y para ello se ofrece la definición propuesta por Bartoll (2012):

Escrito que recoge de manera sincronizada los elementos verbales de un texto audiovisual, tanto orales como visuales, y -según los destinatarios- también los acústicos no verbales, aprovechando las posibilidades que ofrece la traducción interlingüística o intralingüística (Bartoll, 2012, p. 64).

Una de las claves que aporta esta definición es la consideración que se debe tener sobre el tipo de destinatario al que va a ir dirigido el material audiovisual y que, en gran medida, será el que condicione el tipo de subtitulado. Otra referencia interesante e incluida en la definición es la que distingue la traducción interlingüística de la intralingüística, y que permite distinguir los subtítulos interlingüísticos, es decir, en los que existe un cambio de lengua, de los intralingüísticos, en los que no se realiza un cambio de lengua, siguiendo uno de los criterios más extendidos y aceptados entre los profesionales y estudiosos de la traducción audiovisual (Díaz-Cintas, 2003; Díaz-Cintas \& Remael, 2007).

Otro tipo de criterio es el basado en la intención del subtitulado, así Bartoll (2012) diferencia entre subtítulos documentales, que tienen la intención de comunicar en la lengua de destino, e instrumentales, que recogen por escrito toda la información lingüística que transmite el canal oral y se dirigen a personas que quieren aprender idiomas o quieren cantar. Es decir, son subtítulos con finalidad didáctica.

En este artículo, los subtítulos que centran la atención son los intralingüísticos (en los que se mantienen la misma lengua en el audio y en los subtítulos) e instrumentales, es decir, con finalidad didáctica.

\subsection{Experiencias del aprendizaje de la lengua oral y escrita a través de subtítulos}

Los subtítulos intralingüísticos fueron creados originalmente como herramienta de accesibilidad audiovisual para las personas con discapacidad auditiva. Sin embargo, muchas estrategias desarrolladas inicialmente con el objetivo de beneficiar a personas con diferentes necesidades (como trastornos de la comunicación o dificultades motoras) resultaron ser a la larga muy útiles también para el resto, así lo explica Alcantud (2003: 24): «el concepto de ayuda técnica es un concepto ambiguo de forma que muchos útiles que no fueron diseñados como «ayudas técnicas» son «usados» ${ }^{2}$ como tales y lo mismo ocurre al contrario». Un ejemplo de lo expuesto por este autor se puede ver reflejado en

\footnotetext{
${ }^{2}$ Las comillas originales fueron modificadas para facilitar la lectura.
}

un estudio llevado a cabo por el National Captioning Institute (Virginia, EE. UU.) en 1989 sobre el perfil de los usuarios de decodificadores, que reveló que más de la mitad de los decodificadores comprados eran para personas oyentes, muchos de ellos inmigrantes, y solo un $40 \%$ había sido comprado para ser utilizado principalmente por personas con algún tipo de deficiencia auditiva (Neuman \& Koskinen, 1992; Huang \& Eskey 2000; Evmenova, 2008).

En este sentido, ya en 1990, Spanos y Smith llamaron la atención sobre la cada vez mayor introducción de los subtítulos intralingüísticos en el ámbito educativo como herramienta de aprendizaje lingüístico y de la lectura. Los autores destacan la ventaja que supone ver y oír simultáneamente las palabras dentro del contexto de una historia coherente, además de contar con la información aportada por las imágenes que favorece que las palabras sean más reales. Esto es lo que se conoce como redundancia de la información. El material audiovisual subtitulado es una fuente de información muy potente porque proporciona al espectador hasta tres canales diferentes de entrada de la información: las imágenes, la banda sonora ${ }^{3}$ y los subtítulos. En este sentido, cabe destacar que el comportamiento cinético y la comunicación no verbal juegan un papel fundamental en la comprensión oral (Huang \& Eskey, 2000; D’Ydewalle, 2002; Chaume, 2003).

A modo de conclusión de este apartado introductorio, se puede decir que los subtítulos intralingüísticos son muy útiles como herramienta de accesibilidad a los medios para las personas con discapacidad auditiva, pero también está comprobada su eficacia como material didáctico para favorecer el aprendizaje lingüístico tanto oral como escrito, prueba de ello son los ejemplos que se exponen a continuación.

El material audiovisual subtitulado puede ayudar a mejorar la competencia lingüística de los receptores, así se encuentran ejemplos de este uso con usuarios con perfiles variados:

\section{Personas con discapacidad auditiva}

Los subtítulos para las personas con discapacidad auditiva no solo son una herramienta de accesibilidad a los medios audiovisuales, sino que también les permiten mejorar sus habilidades lectoras, de escritura y, por extensión, de la lengua empleada en los propios subtítulos (Neves, 2005; Bartoll, 2012; Cambra et al. 2010). Muchos autores confirman que las personas con discapacidad auditiva mejoran hasta en un $10 \%$ su capacidad para aprender y retener palabras clave viendo material audiovisual subtitulado, si se compara con resultados obtenidos con la utilización de materiales impresos tradicionales (Shulman, 1979; Koskinen, Wilson, Gambrell \& Jensema, 1987; Steinfeld, 1999; Linebarger et al., 2007). Decker y Montandon (1984) van más allá cuando aseguran que cualquier objetivo que se preten-

\footnotetext{
${ }^{3}$ La banda sonora incluye los diálogos, la música y los efectos. Extraído de: http://www.xtec.cat/ xripoll/glosario.htm [Consultado el 27/03/2015].
} 
da trabajar con un texto se puede conseguir igualmente con material audiovisual subtitulado pero de una forma más lúdica y atractiva. En el apartado 3.1 de este artículo, se profundizará sobre las posibles ventajas que aporta este tipo de material a las personas con discapacidad auditiva aplicado en un contexto logopédico.

\section{Estudiantes de lenguas extranjeras}

Hay muchas razones para creer que la televisión subtitulada supone un gran beneficio para los estudiantes de lenguas extranjeras. El uso de películas subtituladas con el objetivo de aprender una lengua extranjera abre nuevos caminos de cara a desarrollar las cuatro habilidades lingüísticas básicas: la comprensión oral, la conversación, la comprensión lectora y la escritura. El material audiovisual subtitulado aporta muchas ventajas; la presencia del contexto lingüístico y el doble input de entrada de la información (auditivo-visual) son dos de las principales características que hacen de los subtítulos un material con un gran potencial didáctico (Goldman, 1993; Borras \& Laffayete, 1994; Baltova, 1999; King, 2002; Bachetti, 2003; Sokoli, 2006; Talaván, 2006; Cambra et al., 2010; Ghia, 2011; DíazCintas, 2012). Programas como Learning via Subtitling (LvS) son un claro ejemplo del uso que se le puede dar a los subtítulos dentro del aula de aprendizaje de segundas lenguas (L2), (Sokoli, 2006).

\section{Personas con competencia lectora baja}

También encontramos ejemplos de su utilidad como herramienta para favorecer la competencia lectora en países en los que existe un alto índice de analfabetismo, ${ }^{4}$ por ejemplo, en la India, y prueba de ello es el exitoso proyecto The Same Language Subtitling (Kothari, 2007; Kothari \& Bandyopadhyay, 2014), cuyos resultados demuestran el gran potencial que tiene el material audiovisual subtitulado para fomentar una actitud positiva ante la lectura. La idea fundamental de The Same Language Subtitling es «lo que lees es lo que oyes» y nació con el objetivo de suplir la falta de oportunidades para practicar la lectura, es decir, su objetivo era ser la excusa diaria de la población de la India para leer. Se podría decir que la base está en generar demanda de lectura, en crear oportunidades de leer a quien no tiene la motivación suficiente para hacerlo por su cuenta, en ocasiones debido a las grandes dificultades que le plantea.

\section{Niños en proceso de aprendizaje de la lectura con o sin dificultades}

Son muchos los autores que ven en el uso del material audiovisual subtitulado una herramienta con gran potencial para fomentar la lectura tanto en niños con dificultades de aprendizaje como en niños que están en pleno proceso de aprendizaje de la lectura y escri-

\footnotetext{
${ }^{4}$ Según Kothari y Bandyopadhyay (2014), en la India no se puede considerar a más de un $37 \%$ de la población como lectora funcional, cifra que se aleja enormemente de los datos oficiales en los que se habla de un $68,7 \%$.
}

tura (Koskinen et al., 1987; Linebarger, 2006; Linebarger et al. 2007; Moses, 2008; Jennings, Hooker \& Linebarger, 2009). El éxito de esta técnica como material eficaz para estimular el proceso de aprendizaje de la lectura radica en el hecho de que contribuye a incrementar la motivación de los niños de cara a enfrentarse a un nuevo aprendizaje (Linebarger et al., 2007; Linebarger, Taylor-Piotrowski \& Greenwood, 2010).

En general, los autores señalan que el uso reiterado y frecuente de los subtítulos favorece el aprendizaje lingüístico y esto es atribuido, en gran parte, y tal y como ya se ha mencionado, a que el mensaje verbal es transmitido por dos canales diferentes (auditivo y visual) sumado a la información, no menos importante, que aportan las imágenes (Bachetti, 2003; Chaume, 2003; Sokoli, 2006; Bartoll, 2008).

\section{Aplicación de los subtítulos en el ámbito logopédico}

En el mundo de la logopedia, el uso de los subtítulos como material de intervención no está documentado. No obstante, la logopeda australiana Caroline Bowen recoge en su libro más destacable, Children's SpeechSound Disorders (2009), la posibilidad de utilizarlos para practicar con niños con diferentes trastornos del habla y pone como ejemplo una página web en la que se presenta una canción subtitulada para niños y, a continuación, afirma que para niños algo mayores, el karaoke lento les ofrece la oportunidad de practicar de forma entretenida, (Bowen, 2009). Otro ejemplo lo podemos encontrar en la página web de Neuroaid, un portal dirigido a personas que hayan sufrido un accidente vascular cerebral (AVC) y en el que proponen, ${ }^{5}$ a las personas que padezcan alexia ${ }^{6}$ como consecuencia de la lesión, cuatro maneras de practicar la lectura entre las que se incluye ver la televisión con subtítulos.

Sin embargo, es cierto que no se han encontrado referencias sobre la aplicación de los subtítulos en el ámbito logopédico más allá de una experiencia personal y que podríamos considerar como anecdótica. Se trata de un artículo on-line incluido en la revista digital ADVANCE. ${ }^{7}$ En este artículo, una logopeda estadounidense, Cindy Herold (2008), explica su propia experiencia con los subtítulos de tipo karaoke aplicados con niños con dos perfiles lingüísticos concretos: niños con trastornos del lenguaje, con los que utiliza los subtítulos de tipo karaoke para trabajar la lectura y la escritura, pero no se detiene a explicar la metodología empleada; y niños con trastornos del habla, en este caso, la logopeda concreta un poco más y menciona que su

\footnotetext{
${ }^{5}$ Accesible en: https://www.neuroaid.com/newsletter/june2009.html [Consultado el 27/03/2015].

${ }^{6}$ Según Ardila (1996), la alexia es un trastorno en la capacidad de la lectura causado por una lesión cerebral y con una conservación de la habilidad para escribir.

${ }^{7}$ ADVANCE contiene artículos para profesionales de la salud de diferentes áreas como la logopedia. Accesible en: http://www.advanceweb. com/ [Consultado el 27/03/2015].
} 
primer objetivo es buscar canciones que contengan los sonidos alterados y después trabajarlos con los subtítulos.

La principal ventaja que destaca de los subtítulos es que le permiten «hacer visible» el lenguaje, y pone como ejemplo a niños que omiten fonemas consonánticos en posición final de sílaba, para los que el lenguaje escrito les ayuda a mostrar la existencia de dichos fonemas gracias a la presencia de sus grafías correspondientes representadas en la pantalla. Otra de las ventajas que menciona es la posibilidad de congelar la imagen para reforzar determinados significados, la ortografía o pronunciación entre otros aspectos (Herold, 2008).

El resto de las referencias encontradas se limitan al ámbito escolar, no logopédico, por ello surgió el interés en valorar la adecuación del material audiovisual subtitulado aplicable en un contexto logopédico y se llevó a cabo un estudio de casos de 6 niños oyentes de 7 y 8 años y con diferentes dificultades en el aprendizaje del lenguaje escrito ${ }^{8}$ (Porteiro, 2012). ${ }^{9}$

En este sentido, resulta necesario aclarar que el material que se diseñó estaba pensado para ser manipulado por un logopeda en un contexto de intervención, y elaborado a partir de las necesidades específicas y de los intereses del destinatario en cuestión. La propuesta era utilizar los subtítulos como apoyo del texto oral para trabajar cuatro objetivos (ortografía natural, ortografía arbitraria, fluidez lectora, atención y memoria auditivas). Además de la redundancia lingüística favorecida por el uso del doble canal de entrada de la información (auditivo-visual), reforzada a su vez por el contexto visual proporcionado por las imágenes, se utilizaron estrategias de tratamiento del texto escrito (uso de colores o huecos) para destacar la información lingüística clave objeto de trabajo.

Otra de las diferencias de la propuesta con respecto al material audiovisual subtitulado tradicional era la posibilidad de congelar la imagen o repetir las secuencias por parte del logopeda para incidir en los aspectos que pudieran presentar mayor nivel de dificultad, ya que la finalidad de los subtítulos no era simplemente disfrutar del texto audiovisual, sino favorecer un aprendizaje lingüístico. Este hecho diferencial ya había sido destacado por autores como Decker y Montandon (1984) y Bartoll $(2008,2012)$ en referencia a los subtítulos con finalidad didáctica.

La principal conclusión obtenida de la realización de las pruebas mencionadas (Porteiro-Fresco, 2012) fue que resulta determinante la familiarización tanto con el propio material como con los subtítulos para incrementar su eficacia como herramienta de intervención. El rendimiento en la lectura fue en aumento a medida

\footnotetext{
${ }^{8}$ Uno de los niños presentaba además retraso leve del lenguaje y otro rotacismo.

${ }^{9}$ Esta investigación fue posible gracias a la financiación de la Agència de Gestió d'Ajuts Universitaris i de Recerca mediante la concesión de la beca FI-DGR Resolución IUE/2681/2008, de 8 de agosto (DOGC, núm. 5208, de 3.9.2008)
}

que los niños se iban adaptando al nuevo recurso. Así, la familiarización es entendida en dos sentidos: con el nuevo soporte y con el contenido lingüístico. Los dos niños que repitieron la experiencia siguieron estrategias diferentes en los últimos ejercicios, fruto del aprendizaje realizado durante la primera prueba. Desde el inicio, su atención se centró principalmente en los subtítulos, trataron de memorizar los textos y prestaron especial atención a la información destacada con colores, es decir, a la información clave seleccionada previamente bajo la supervisión de la logopeda. El otro tipo de familiarización tiene que ver con el contenido lingüístico, que favoreció que en todos los casos se notase una mejora en la lectura expresiva a medida que iban conociendo, y en algunos casos memorizando, los diálogos del material. El hecho de que la lectura se realizase en una segunda proyección, les permitía en algunos casos adelantarse a ella y ganar seguridad con respecto al texto escrito, lo que resultó clave para fomentar la autoestima y motivación de algunos niños.

Pero no todos los resultados de esta primera prueba fueron positivos, también surgió la necesidad de realizar modificaciones tanto del propio material y de las actividades sugeridas para explotarlo, como del planteamiento propuesto para su aplicación, todo ello con el objetivo de optimizar su nivel de eficacia como material explotable en el ámbito de la intervención logopédica.

\subsection{Subtítulos y aprendizaje de la lectura en un contexto logopédico con niños con discapacidad auditiva}

En la experiencia descrita en el apartado anterior (Porteiro, 2012) se incluyeron niños con diferentes necesidades lingüísticas pero todos ellos oyentes. En este sentido, el objetivo de este artículo es plantear la posibilidad de aplicar este tipo de material (material subtitulado con finalidad didáctica) a niños con discapacidad auditiva y dejar la puerta abierta a analizar, en un futuro estudio, sus efectos a la hora de favorecer el aprendizaje de la lengua escrita y, por extensión, de la lengua oral en un contexto de intervención logopédica.

Como ya se ha mencionado, los subtítulos son una herramienta de accesibilidad audiovisual para el colectivo de personas con discapacidad auditiva, aunque resulta fundamental entender que los subtítulos para personas sordas (SPS) están dirigidos a un perfil muy determinado: usuarios oralistas con índices de alfabetización medio-alto y destrezas lectoras elevadas (Arnáiz, 2012). Y, en este sentido, conviene recordar que no todos los posibles usuarios de este material tienen la misma formación, competencia lectora y ni tan siquiera disponen de una competencia lingüística similar (Neves, 2005; Alegría \& Domínguez, 2009; Herrera, 2009; Romero-Fresco, 2009; Domínguez, Rodríguez \& Alonso, 2011; Arnáiz, 2012; Gutiérrez, 2012).

El uso de subtítulos no siempre garantiza la comprensión íntegra del material audiovisual por parte de las personas con discapacidad auditiva y esto es mucho 
más evidente en el caso de los niños (Neves, 2005; Cambra et al., 2010; Zárate, 2010). El bajo nivel de comprensión lectora, junto con la excesiva velocidad con la que aparecen los subtítulos en la pantalla, parecen ser las causas que determinan que la técnica del subtitulado, tal y como se está llevando a cabo hasta ahora, no siempre pueda ser considerada la mejor técnica de accesibilidad audiovisual para este colectivo (Cambra, 2006; Cambra, Silvestre \& Leal, 2008; Cambra et al., 2010). Las autoras fundamentan esta idea en los resultados de varios estudios realizados con niños y adolescentes con sordera. El estudio realizado con niños de 6 y 7 años les permitió concluir que la velocidad lectora exigida para entender los dibujos animados superaba la velocidad media de palabras por minuto que cualquier niño de primero y segundo de primaria tiene que leer en correspondencia con su edad (Cambra, 2006). Y el estudio realizado con adolescentes de 12 a 19 años reflejó también las dificultades que presentaron para acceder a la información audiovisual, tanto con subtítulos como sin ellos, y las razones parecían estar en el bajo nivel de comprensión lectora, pero también en la excesiva velocidad de los subtítulos (Cambra et al., 2008; Cambra et al., 2010). No obstante, en un estudio posterior, las autoras afirman que:

La complementariedad de los subtítulos es imprescindible para los/las adolescentes con sordera, llegando incluso estos a expresar un mayor número de contenidos del documental que los adolescentes oyentes y desapareciendo las diferencias entre ambos grupos en cuanto al número de referencias al contenido de las distintas partes del documental. En este sentido, coincidiendo con los resultados hallados en otros estudios (...), el nivel de comprensión lectora contribuye positivamente (Cambra, Silvestre \& Leal, 2013, p. 106).

Lo que señalan las autoras es que la influencia de la familiaridad del contenido, el conocimiento del léxico y la capacidad para memorizar la información pueden considerarse también importantes en la comprensión de los textos audiovisuales. Prueba de ello es que en otro estudio, en el que elaboraron varios guiones de unos 80 segundos con diferentes niveles de subtítulos y los validaron con una muestra piloto de 11 niños sordos de $2 .^{\circ}, 3 .^{\circ}$ y $5 .^{\circ}$ de primaria, los resultados les permitieron afirmar que los dibujos animados con subtítulos adaptados para facilitar la comprensión del alumno sordo se pueden considerar un instrumento de aprendizaje útil para utilizarlo tanto en el colegio como en el ámbito familiar (Cambra et al., 2010).

Los subtítulos favorecen que la lengua sea visible (Jelinek \& Jackson, 2001, Van Lommel, Laenen, D’Ydewalle, 2006; Linebarger et al., 2007). El paso de material lingüístico oral a escrito puede suponer a los niños con discapacidad auditiva una ayuda para el aprendizaje de nuevas palabras, ya que en el momento en que el estudiante es más consciente de la estructura de las palabras, le resulta más fácil acceder al significado, todo ello reforzado por la ayuda, no menos impor- tante, del contexto (Decker \& Montandon, 1984; Steinfeld, 1999; Cambra et al., 2008).

Con el paso de los años, los profesores cada vez son más conscientes del gran potencial educativo del material audiovisual subtitulado para los alumnos con discapacidad auditiva (Parks, 1994; Robertson \& Erler, 2005; Zárate, 2008). Los profesores pueden ayudar a los niños a mejorar su competencia lectora gracias al material audiovisual subtitulado, pero además, pueden explotarlo para aumentar su conocimiento del mundo y enriquecer sus experiencias lingüísticas (Jelinek, 1999; Koolstra \& Beentjies, 1999). Incluso hay autores que consideran que es positivo utilizar los subtítulos con niños que todavía no poseen una competencia lectora consolidada, a pesar de que en un principio puede que no les hagan demasiado caso, pero su uso favorece que se vayan familiarizando con el lenguaje escrito y con la propia presencia de los subtítulos (Stark, 2010).

Hay que recordar que tradicionalmente se identificó el desconocimiento del lenguaje oral como uno de los principales obstáculos en el aprendizaje de la lectura en los alumnos con discapacidad auditiva. Sin embargo, los estudios más recientes han centrado su interés en los procesos cognitivos implicados en dicho aprendizaje. En este sentido, algunos autores señalan que las dificultades en la lectura de este colectivo se pueden explicar también debido a problemas en la aplicación de las reglas de correspondencia grafemafonema (RCGF) y en la capacidad de almacenamiento de la memoria a corto plazo (MCP) (Herrera, 2009).

Por una parte, según, Alegría y Domínguez (2009: 3) «ser capaz de reconocer una palabra escrita, es decir conectar la serie de letras que la componen con su significado previamente establecido es una actividad específica de la lectura en la media en que no sirve sino para leer». Numerosos estudios demuestran que los alumnos con discapacidad auditiva que poseen mejores habilidades lectoras son los que tienen mayores niveles de conciencia fonológica, aunque esta capacidad es inferior a la alcanzada por los alumnos oyentes de la misma edad. El dominio de las RCGF y las habilidades de segmentación son fundamentales para el proceso de aprendizaje de la lectura, ya que ambos mecanismos permiten el establecimiento de una estrategia alfabética de lectura (Alegría \& Domínguez, 2009; Herrera, 2009; Domínguez et al., 2011: 4).

Por otra parte, la memoria, junto con la atención y la percepción, forman parte de los procesos psicológicos básicos y se presenta como uno de los procesos cognitivos primordiales implicados en el aprendizaje de la lectura y de cualquier otro aprendizaje. En general, a los alumnos con discapacidad auditiva se les atribuye una capacidad de memoria menor que a los oyentes, explicado en gran parte por un uso menos eficiente de los códigos fonológicos en la MCP, o memoria de trabajo, o a que emplean códigos de memoria cualitativamente distintos a los utilizados por los oyentes (Herrera, 2009).

En este sentido, Herrera (2009) sugiere que la mejora de las habilidades de MCP y RCGF en los alumnos 
con discapacidad auditiva requiere integrar en el proceso de aprendizaje de la lectura y la escritura «la utilización de todas las modalidades sensoriales que faciliten la vinculación de la información gráfica proveniente del texto escrito, con códigos de procesamiento de la información basados en experiencias visuales, signadas, dactílicas ${ }^{10}$ y ortográficas que les permitan acceder a la información escrita» (Herrera, 2009: 90), es decir, que se deberían posibilitar todas las vías de acceso a la información para que puedan crear vínculos que les permitan representar la información grafema-fonema, y en este sentido el material audiovisual subtitulado se presenta como una buena herramienta capaz de proporcionar este tipo de información.

Para concluir este apartado, hay que decir que la propuesta que recoge este artículo, y que se presenta a continuación, es la de utilizar el material audiovisual subtitulado de una forma adaptada y bajo la supervisión de un logopeda que ejerza de editor del material (con su conocimiento de las necesidades específicas del usuario en cuestión y unos objetivos claros de trabajo) y de ejecutor, es decir, como guía a la hora de aplicarlo y de establecer una metodología de trabajo con el nuevo material, es por ello que el obstáculo planteado por la excesiva velocidad de los subtítulos, queda mitigado con un uso diferente al que se le da cuando se utiliza como material de accesibilidad audiovisual.

\subsection{Propuestas para elaborar material audiovisual subtitulado aplicable en un contexto logopédico}

Entre los autores que defienden la aplicación del material audiovisual subtitulado con finalidad didáctica con personas con discapacidad auditiva destacan Decker y Montandon, que ya en 1984, mencionaron la necesidad de adaptarse a dos requisitos fundamentales para poder llevarlo a la práctica. El primer requisito tiene que ver con el propio profesional encargado de su ejecución que deberá visualizar el material previamente para familiarizarse con él y predecir las posibles escenas que puedan plantear discusión. El segundo de los requisitos es más de tipo técnico y se refiere a la posibilidad de utilizar la pausa o repetir determinadas secuencias para formular preguntas, resolver dudas, discutir sobre alguna cuestión o añadir alguna explicación lingüística o de la narración con más detenimiento. De esta manera, se facilita que el destinatario incida sobre un contenido concreto, de la misma manera que un lector puede releer un párrafo o una página que no le haya quedado suficientemente clara. En este sentido, tal y como ya se ha mencionado en un apartado anterior, actualmente otros autores también llaman la atención al respecto como elemento diferenciador del

\footnotetext{
${ }^{10}$ Referido al alfabeto dactilológico, que equivale al alfabeto manual, consiste en hacer configuraciones manuales para representar las letras del alfabeto. Cada grafema o letra escrita tiene su correspondiente forma manual. Accesible en: https://www.uam.es/personal_pdi/psicologia/agonzale/Asun/2006/Libros/SistemasAlternatComunic/cap5bimo.pdf [Consultado el 27/03/2015].
}

material audiovisual subtitulado con finalidad didáctica frente a un uso más tradicional (Bartoll, 2008 \& 2012).

Otra ventaja que se puso de manifiesto con la realización de las primeras pruebas en el ámbito logopédico (Porteiro-Fresco, 2012) es la posibilidad de realizar un material interactivo, es decir, que los usuarios tengan la capacidad de modificar los subtítulos bien por demanda del logopeda o por deseo propio. Así, el papel de los usuarios pasaría a ser activo y no solo la del mero espectador. Haciendo uso de programas de edición accesibles y asequibles se les podría dar la opción de cambiar el tipo de fuente, tamaño o incluso los efectos empleados (colores, karaoke, huecos, etc.) y de esta manera pasarían a tomar sus propias decisiones con lo que se estaría reforzando su autonomía y, por extensión, su autoestima. En este sentido, Díaz-Cintas (2012) también destaca esta opción como un valor añadido del propio material aplicado en el contexto del aprendizaje de una lengua extranjera:

La explotación tradicional de este recurso se ha limitado al visionado por parte del alumno de material audiovisual subtitulado y, aunque los resultados alcanzados por muchos estudios empíricos demuestran su validez en el aprendizaje de la lengua extranjera por los motivos aducidos en las páginas anteriores, una de sus desventajas podría ser la pasividad inherente a esta actividad (...) El salto a la web 2.0 ha traído consigo la aparición de programas gratuitos de subtitulación y ha hecho que trabajar con material audiovisual sea mucho más fácil. Todo ello ha abierto nuevas posibilidades didácticas, más activas y dinámicas (...) Por su novedad, este tipo de actividad presenta aspectos marcadamente positivos que se ven reforzados por su eminente enfoque lúdico, lo que a su vez funciona como un poderoso aliciente en la motivación y participación del alumnado (Díaz-Cintas, 2012, p. 111).

Y sin duda, otra de las ventajas de esta técnica es que permite adaptarse a las necesidades e intereses de los usuarios, lo que favorece la elección de un material que se ajuste a la franja de edad y a los gustos de los usuarios con los que se pretende trabajar. La clave está en que se puede elegir cualquier material audiovisual accesible desde un ordenador, y que incluso puede ser grabado por el propio logopeda para que se adapte mejor a los objetivos de trabajo, y ajustarlo a las necesidades del niño con el diseño de subtítulos adaptados (en la medida en que se utilicen técnicas de tratamiento del texto escrito para destacar la información lingüística objeto de trabajo) y actividades relacionadas para poder explotar el material.

Y como ejemplo de este tipo de aplicación, seguidamente se incluye una breve propuesta de ejercicios para trabajar la lectura y escritura con niños con discapacidad auditiva (Porteiro-Fresco, 2012):

- Asociación fonema-grafema. Con diferentes colores se destacan las grafías correspondientes a los fonemas objeto de trabajo, lo que permitirá que en ocasiones una misma grafía se encuentre asociada a dos colores 
diferentes dependiendo del fonema que represente (por ejemplo, la grafía $c$ iría destacada con un color diferente dependiendo de si fuera asociada al fonema $/ \mathrm{k} / \mathrm{o} / \theta /$, en el caso del catalán /s/). Si además se quiera trabajar la articulación, se puede detener el vídeo y pedir al niño que lea los subtítulos con el «recordatorio» de los colores que favorecerá la correcta articulación de los fonemas alterados (ver Figura 1). En una segunda versión del material se pueden omitir las grafías y que sea el niño quien, con o sin ayuda del audio, deba recuperarlas (ver Figura 2). En esta misma línea de trabajo, se podrían destacar las consonantes en posición final de sílaba (atribuyéndoles un código de colores que se ajustara al nivel de dificultad del niño) o destacarlas dentro del grupo consonántico.

- Atención y memoria auditivas. En una primera versión se pueden destacar con colores unas palabras clave que, en una segunda versión, se omitirán, para que sean los niños los que completen los huecos. En una primera fase, se realizará con la ayuda del audio y, en una segunda, de la lectura del propio subtítulo, es decir, del contexto lingüístico y, por lo tanto, recuperando la palabra de su memoria. En el caso de que se quisiera realizar un trabajo de lenguaje, se podría pedir que se completen los subtítulos con otras opciones lingüísticas diferentes pero igualmente válidas para cada contexto determinado (ver Figura 3).

- Lectura. Se pueden editar subtítulos de tipo karaoke (se van destacando con un color a medida que el discurso avanza) para trabajar el ritmo y fluidez de la lectura $^{11}$ (ver Figura 4), y además destacar con un color diferente las sílabas, palabras u oraciones clave o que puedan resultar más complicadas de leer (ver Figura 5). Otro efecto sería el llamado teatro en el que se destacan los subtítulos asociados a cada personaje con un color determinado para favorecer la lectura al unísono, en compañía del audio o del propio logopeda. Se trata de asignarle a cada usuario un personaje y se favorece así el trabajo de los turnos. En los últimos años se han incrementado los estudios relacionados con la técnica de la lectura al unísono y su efecto en la fluidez lectora (Hudson, Lane \& Pullen, 2005), así hay autores que aseguran que «la investigación sobre lectura indica que las técnicas de lectura oral asistida, leer mientras se oye una lectura fluida del mismo texto realizada por otro lector, puede favorecer una mejora en la fluidez lectora y en general en todo el proceso de lectura» (Rasinski, 2009, p. 13) (Figura 6).

Este tipo de ejercicios realizados bajo la supervisión de un logopeda y diseñados con unos objetivos preestablecidos y personalizados para cada usuario no son más que un breve ejemplo del potencial que ofrece la técnica del subtitulado. Lo que se pretende con este artículo es demostrar que puede ser explotado como

${ }^{11}$ En este caso el logopeda podría optar por realizar las grabaciones a un ritmo más adecuado al niño.
Figura 1. Asociación fonema-grafema.

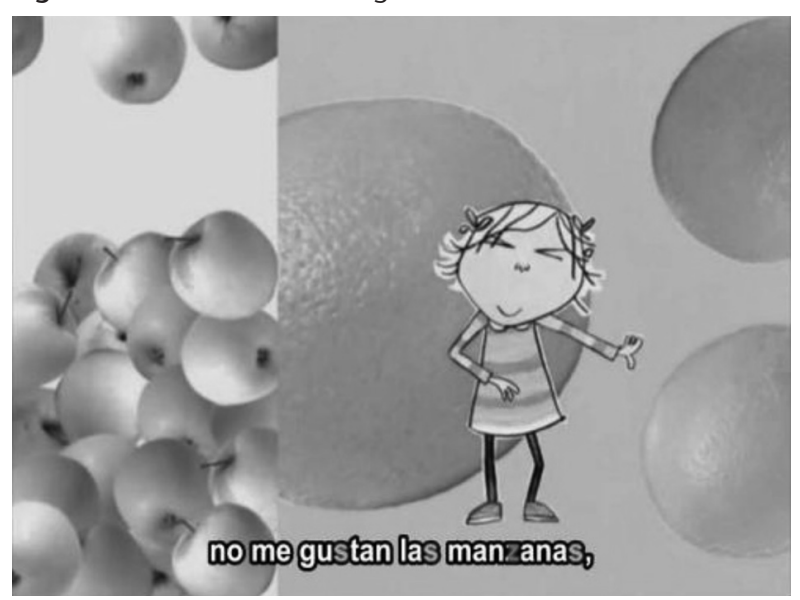

Figura 2. Huecos grafías.

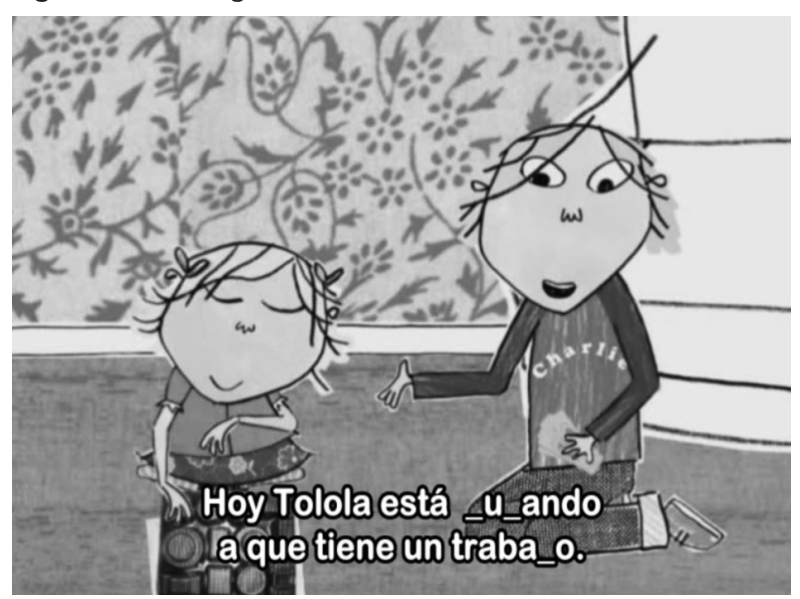

Figura 3. Huecos palabras.

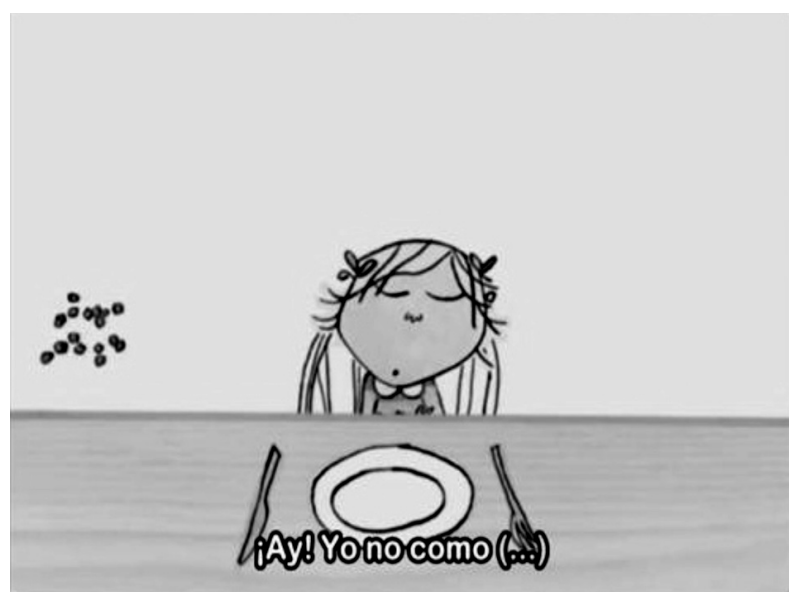

una nueva fuente rica en material lingüístico variado y motivador y que puede ayudar a los logopedas a generar recursos adaptables a las necesidades lingüísticas y preferencias de los pacientes.

\section{Conclusiones}

El material audiovisual subtitulado es una herramienta con un gran potencial extrapolable al ámbito de la educación, tal y como se ha visto en los apartados previos. Este hecho, sumado a la cada vez mayor nece- 
Figura 4. Karaoke.

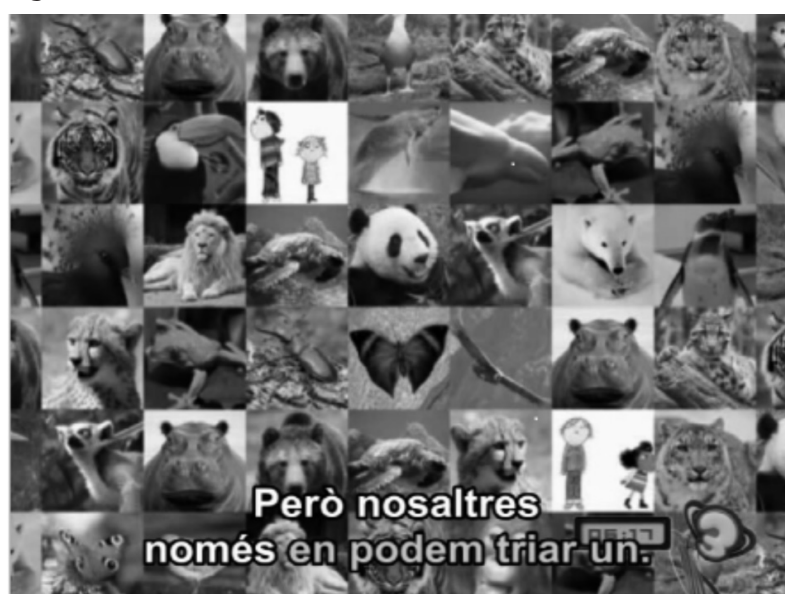

Figura 5. Palabras clave más efecto karaoke.

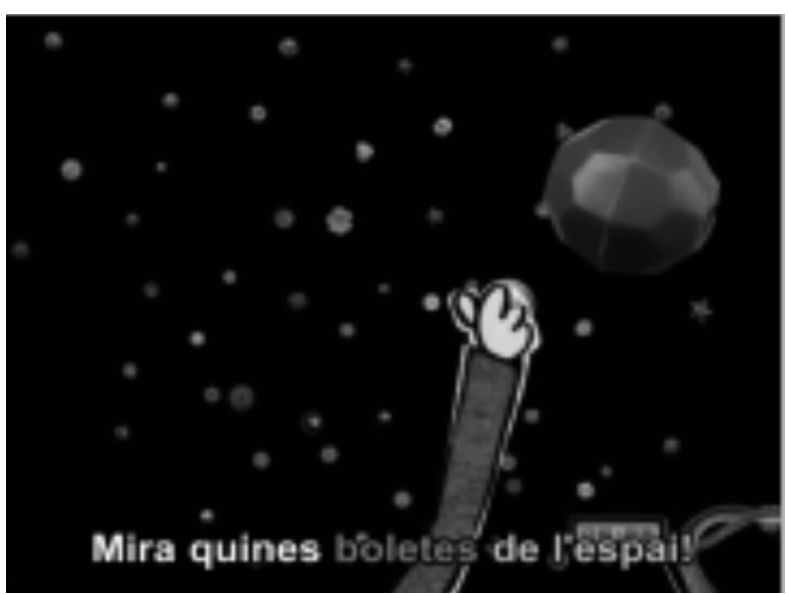

Figura 6. Teatro.

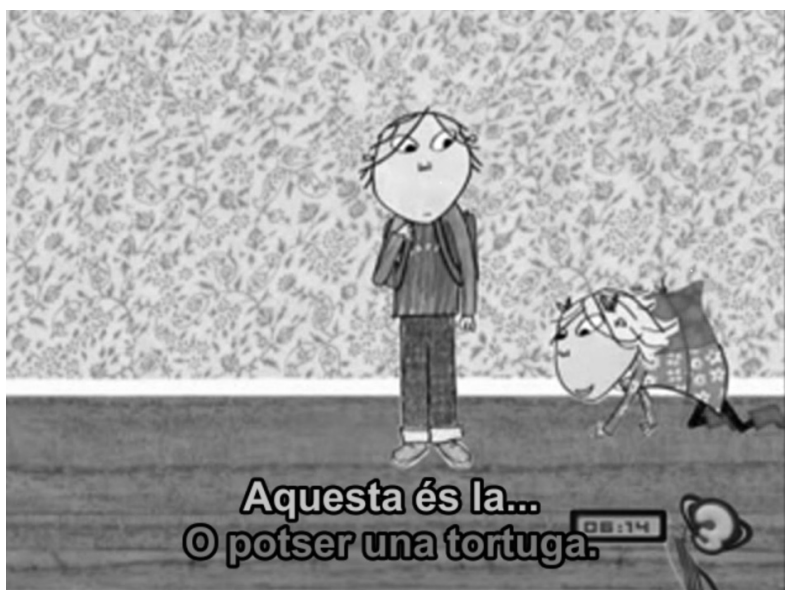

sidad de encontrar recursos que permitan a los logopedas diseñar material adaptable a las exigencias y preferencias de sus pacientes y de la actual sociedad de la información, es lo que ha favorecido que se haya planteado la posibilidad de aplicar material audiovisual subtitulado en el ámbito logopédico.

En el caso de los niños con discapacidad auditiva, el material audiovisual subtitulado no solo es un material que les facilita acceder a la información de una forma más sencilla, sino que también les puede ayudar a mejorar sus habilidades lingüísticas tanto orales como escritas. En este sentido, el material audiovisual se caracteriza por aportar un input entendible y atractivo por medio de una experiencia multisensorial que permite captar la atención de los usuarios.

El objetivo de este artículo era recoger algunas de las posibilidades que ofrece el material audiovisual subtitulado para trabajar la lectura y la escritura, y por extensión el lenguaje, en el caso de niños con discapacidad auditiva y demostrar así la flexibilidad y capacidad de adaptación de la técnica para elaborar actividades explotables desde el ámbito logopédico, dejando la puerta abierta a la realización de futuros estudios experimentales con el fin de demostrar su eficacia en el nuevo campo y con una finalidad muy concreta, servir de material de complementario para logopedas para mejorar las habilidades lectoras y de escritura de los niños con discapacidad auditiva.

\section{Referencias}

Alcantud, F. (2003). Las tecnologías de ayuda: concepto y modelo de intervención. En F. Alcantud \& F.J. Soto (Eds.), Tecnologías de ayuda en personas con trastornos de comunicación (pp. 19-30). Barcelona: Nau Llibres.

Alegría, J. \& Domínguez, A.B. (2009). Los alumnos sordos y la lengua escrita. Revista Latinoamericana de Educación Inclusiva, 3(1), 95-111.

Ardila, A. (1996). Las afasias. Department of Communication Sciences and Disorders Florida International University Miami, Florida, EE.UU.

Arnáiz, V. (2012). Los parámetros que identifican el subtitulado para sorods. Análisis y clasificación. MonTI, 4, 103-132.

Bachetti, P. (2003). The Impact of Learning Style on the French Second Language Acquisition on English Speaking Learners Exposed to a French and English Standard and Reversed Subtitled Film. [Recuperado el 03/01/2015 de http://es.scribd.com/doc/134242217/20295293Speaking-Style\#scribd].

Baltova, I. (1999). Multisensory Language Teaching in a Multidimensional Curriculum: The Use of Authentic Bimodl Video in Core French. The Canadian Modern Language Review/La Review canadienne des langues vivante, 56(1), 32-48.

Bartoll, E. (2008). Paràmetres per a una taxonomia de la subtitulació. (Tesis doctoral en línea). Universitat Pompeu Fabra. Barcelona. Recuperado el 03/01/2015 de http://hdl.handle.net/10803/7572.

Bartoll, E. (2012). La subtitulació. Aspectes teòrics i pràctics. Vic: Eumo.

Borras, I. \& Laffayete, R. (1994). Effects of multimedia course subtitling on the speaking permormance of college students in French. The Modern Language Journal, 78(1), 61-75.

Bowen, C. (2009). Children's Speech Sound Disorders. Oxford: WileyBlackwell.

Brett, P. \& Nash, M. (1999). Multimedia language learning courseware: a design solution to the productions series of CD-ROMs. Computers and Education, 32, 19-33. 
Cambra, C. (2006). Los subtítulos en televisión: ¿facilitan a los adolescentes sordos la comprensión de los programas? FIAPAS, 110, 28-31.

Cambra, C., Silvestre, N. \& Leal, A. (2008). Función de la subtitulación y la interpretación de la imagen en la comprensión de los mensajes televisivos: la comprensión de una serie por parte de los adolescentes sordos. Cultura y Educación, 20(1), 81-93.

Cambra, C., Silvestre, N. \& Leal, A. (2010). Elaboració de material audiovisual subtitolat per motivar la lectura a l'alumnat amb sordesa. Recuperado el 03/01/2015 de http://www.cac.cat/pfw_files/cma/recerca/estudis_recerca/Material_audiovisual_subtitulat_ lectura_i_alumnat_sord.pdf.

Cambra, C., Silvestre, N. \& Leal, A. (2013). La interpretación de los adolescentes sordos y oyentes de un documental audiovisual: importancia del subtitulado. Revista de Logopedia, Foniatría y Audiología, 33(3), 99-108.

Chaume, F. (2003). Doblatge i subtitulació per a la TV. Barcelona: Eumo Editorial.

Danan, M. (2004). Captioning and Subtitling: Undervalued Language Learning Strategies. META, 49(1), 67-77.

Decker, N. \& Montandon, B. (1984). Captioned Media in the Classroom. Springfield: National Association of the Deaf.

Díaz-Cintas, J. (2003). Teoría y práctica de la subtitulación: Inglés-Español. Barcelona: Ariel.

Díaz-Cintas, J. (2012). Los subtítulos y la subtitulación en la clase de lengua extranjera. Abehache, Revista da Associação Brasileira de Hispanistas, 3, 95-14.

Díaz-Cintas, J. \& Remael, A. (2007). Audiovisual Translation: Subtitling. Manchester: St. Jerome.

Domínguez, A.B.; Rodríguez, P. \& Alonso, P. (2011). Cómo facilitar el aprendizaje de la lectura de niños sordos. Importancia de las habilidades fonológicas. Revista de Educación, 356, 353-357. doi: 10.4438/1988592X-RE-2011-356-043

Evmenova, A. S. (2008). Lights! Camera! Captions! The Effects of Picture and/or Word Captioning Adaptations, Alternative Narration, and Interactive Features on Video Comprehension by Students with Intellectual Disabilities. (Tesis doctoral en línea). George Mason University. Virginia. [Recuperado el 03/01/2015 de http://digilib.gmu.edu/jspui/bitstream/1920/3071/1/Evmenova_Anna.pdf].

Ghia, E. (2011). The acquisition of $\mathrm{L}$ «syntax through audiovisual translation». En A. Serban, A. Matamala \& J. M. Levaur (Eds.). Audiovisual Translation in CloseUp (pp. 95-112). Berna, Berlín, Bruselas, Frankfurt am Main, Nueva York, Oxford, Viena: Peter Lang.

Goldman, M. (1993). Using Captioned TV for Teaching Reading. Recuperado el 03/01/2015 de http://files. eric.ed.gov/fulltext/ED366935.pdf

Gutiérrez, R. (2012). Análisis del proceso de transcripción en la expresión escrita de alumnos sordos. Revista Complutense de Educación, 23(2), 331-346.

Herrera, V. (2009). Procesos cognitivos implicados en la lectura de los sordos. Estudios Pedagógicos XXXV, 1, 79-92.
Herold, C. (2008). Fun with karaoke. ADVANCE for Speech-Language Pathologist and Audiologist, 18(22), 5.

Huang, H. \& Eskey, D. (2000). The effects of closedcaptioned television on the listening comprehension of intermediate English as a second language (ESL) students. J. Educational Technology Systems, 28(1), 75-96.

Hudson, R.F., Lane, H.B. \& Pullen, P.C.(2005). Reading fluency assessment and instruction: What, why, and how? The Reading Teacher, 58(8), 702-714.

Jelinek, M.S. (1999). Television captioning: a vehicle for accessibility and literacy. Technology and Persons with Disabilities Conference Proceedings. [Recuperado el 03/01/2015 de http://www.dinf.ne.jp/doc/english/ Us_Eu/conf/csun_99/session0057.html].

Jelinek, M., \& Jackson, D. (2001). Television Literacy: Comprehension of Program Content Using Closed Captions for the Deaf. Journal of Deaf Studies and Deaf Education, 6(1), 43-53.

Jennings, N.A., Hooker, S.D., \& Linebarger, D.L. (2009). Educational television as mediated literacy environments for preschoolers. Learning Media and Techonology, 34(3), 229-242.

King, J. (2002). Using DVD feature films in the EFL classroom. The weekly column, 88 Recuperado el 03/01/2015 de http://www.eltnewsletter.com/back/ February2002/art882002.htm

Koolstra, C. \& Beentjies, J. (1999). Children's Vocabulary Acquisition in a Foreign Language through Watching Subtitled Television Programs at Home. Educational Technology Research \& Development, 47(1), 51-60.

Koskinen, P., Wilson, R., Gambrell, L. \& Jensema, C. (1987). Using the Technology of Closed-Captioned Television to Teach Reading to Handicapped Students. Performance Report. [Recuperado el 03/01/2015 de http:// files.eric.ed.gov/fulltext/ED314891.pdf].

Kothari, B. (2007). Reading for a Billion: Same Language Subtitling on TV-India. Making a Difference: Effective Practices in Literacy in Africa (pp. 45-46). Hamburgo: UNESCO Institute for Lifelong Learning.

Kothari, B. \& Bandyopadhyay, T. (2014). Same language subtitling of Bollywood film songs on TV: Effects on literacy. Information Technologies \& International Development, 10(4), 31-47.

Krashen, S. (1985). The input hypothesis: Issues and implications. Nueva York: Longman.

Linebarger, D.L. (2006). Literature review part 2: Teaching language and literacy on television. Philadelphia, PA: Annenberg School for Communication, University of Pennsylvania.

Linebarger, D.L., Taylor-Piotrowski, J. y Vaala, S. (2007). Literature review part 3: Supplementing television: What enhances or detracts from the power of television to teach. Philadelphia, PA: Annenberg School for Communication, University of Pennsylvania.

Linebarger, D.L.; Taylor-Piotrowski, J. y Greenwood, C. (2010). Onscreen print: The role of captions as a supplemental literacy tool. Journal of Research in Reading 33(2), 148-167. 
Moses, A. (2008). Impacts of television viewing on young children's literacy development in the USA: A review of the literature. Journal of Early Childhood Literacy, 8(1), 67-102.

Naigles, L. \& Mayeux, L. (2000). Television as Incidental Language Teacher. En D. Singer y J. Singer (Eds.), Handbook of Children and the Media (pp.135-152). Thousand Oaks, Londres, Nueva Delhi: Sage Publications.

Neuman, S.B. \& Koskinen, P.S. (1992). Captioned Television as «Comprehensible Input»: Effects of Incidental Word Learning from Context for Language Minority Students. Reading Research Quarterly, 27, 95-106.

Neves, J. (2005). Audiovisual Translation: Subtitling for the Deaf and Hard-of-Hearing (Tesis doctoral en línea). Universidad de Roehampton. Londres. Recuperado el 03/01/2015 de http://roehampton.openrepository. com/roehampton/bitstream/10142/12580/1/ neves\%20audiovisual.pdf.

Parks, C. (1994). Closed Captioned TV: A Resource for ESL Literacy Education. Recuperado el 03/01/2015 de http://www.ericdigests.org/1995-1/tv.htm].

Podszebka, D., Colin, C., Apple, M. \& Windus, A. (1998). Comparison of Video and Text Narrative Presentations on Comprehension and Vocabulary Acquisition. Recuperado el día 03/01/2015 de http://www.eric. ed.gov/PDFS/ED418382.pdf.

Porteiro-Fresco, M. (2012). El subtitulado como herramienta complementaria en la rehabilitación logopédica de patologías lingüísticas. (Tesis doctoral en línea). Universitat Autònoma de Barcelona. Barcelona. Recuperado el 03/01/2015 de http://hdl.handle. net/10803/98410

Posell, A. (1984). Captioned Media for Hearing-Impaired Youngsters: What Parents Need to Know. Recuperado el 03/01/2015 de http://www.eric.ed.gov/PDFS/ ED252996.pdf

Rasinski, T. (2009). Effective Teaching of Reading: From Phonics to Fluency. Recuperado el día 03/01/2015 de http://www.timrasinski.com/presentations/effective_teaching_of_reading-from_phonics_to_fluency_2009.pdf.

Romero-Fresco, P. (2009). More haste less speed: Edited versus verbatim respoken subtitles. VIAL ,6, 109-133.

Robertson, B. \& Erler, K. (2005). Automated Captioning of Streaming Media: Quick, Easy, and Inexpensive. Recuperado el 03/01/2015 de http://www.rit.edu/ wtecsym/papers/2005/T1C.pdf

Shulman, J. (1979). Multi-level captioning; a system for preparing reading materials for the hearing impaired. American annals of the deaf, 124(5), 559-67.

Sokoli, S. (2006). Learning via Subtitling (LvS): A tool for the creation of foreign language learning activities based on film subtitling. MuTra 2006. Audiovisual Translation Scenarios: Conference Proceedings. Recupe- rado el 03/01/2015 de http://www.euroconferences. info/proceedings/2006_Proceedings/2006_Sokoli_ Stravoula.pdf

Spanos, G. \& Smith, J. (1990). Closed Captioned Television for Adult LEP Literacy Learners. Recuperado el 03/01/2015 de http://www.ericdigests.org/pre-9216/ closed.htm

Stark, B. (2010). Read captions across America [Recuperado el día 03/01/2015 de http://readcaptionsacrossamerica.org/articles_read_captions_across_america. html]

Steinfeld, A. (1999). The benefit to the deaf of real-time captions in a mainstream classroom environment (Tesis doctoral en línea). Universidad de Michigan. Recuperado el 03/01/2015 de http://citeseerx.ist.psu.edu/ viewdoc/download;jsessionid=195BFE449A11E7E55 E547690A480F008?doi=10.1.1.3.6757\&rep=rep1\&ty pe=pdf

Talaván, N. (2006). Aplicaciones de la traducción audiovisual para mejorar la comprensión oral del inglés (Tesis doctoral recurso digital). Departamento de Filologías Extranjeras y sus lingüísticas. Facultad de Filología: Universidad Nacional de Educación a Distancia.

Van Lommel, S., Laenen, A. \& D’Ydewale, G. (2006). Foreign-grammar acquisition while watching subtitled television programmes. British Journal of Educational Psychology, 76, 243-258.

D'Ydewalle, G. (2002). Foreign-language acquisition by watching subtitled television programs. Journal of Foreign Language Education and Research, 12, 59-77.

Zárate, S. (2008). Subtitling for Deaf children on British television. The Sign Language Translator and Interpreter, 2, 15-34.

Zárate, S. (2010). Bridging the gap between Deaf Studies and AVT for Deaf children. En J. Díaz-Cintas, A. Matamala y J. Neves (Eds.), New Insights into Audiovisual Translation and Media Accesibility. Media for All 2 (pp.159-174). Ámsterdam-Nueva York: Rodopi.

\section{Aplicació del subtitulat com a eina logopèdica per treballar el llenguatge escrit amb nens amb discapacitat auditiva}

Resum. En la societat de la informació actual en què vivim immersos, l'ús de mitjans audiovisuals amb finalitat docent està molt estès, en aquest sentit se'n pot destacar l'ús dels subtítols, que ofereixen un gran potencial didàctic reconegut. Aquest fet, sumat a la necessitat cada cop més elevada de trobar recursos que permetin als logopedes dissenyar material adaptable a les exigències i preferències dels seus pacients és el que ha afavorit que s'hagi plantejat estendre l'ús d'aquesta tècnica a l'àmbit logopèdic. L'objectiu d'aquest article, per tant, és oferir una proposta per treballar l'aprenentatge de la lectura i l'escriptura amb nens amb discapacitat auditiva aplicant material audiovisual subtitulat $i$ en un context logopèdic.

Paraules clau: subtitulat, lectoescriptura, logopèdia, sordesa 
